\title{
Caracterização morfoanatômica de raiz e rizoma de Symphytum officinale L. (Boraginaceae)
}

\author{
Ana Cristina O. Toledo ${ }^{1 *}$, Márcia R. Duarte ${ }^{2}$,Tomoe Nakashima ${ }^{2}$ \\ ${ }^{1}$ Departamento de Ciencias Farmacêuticas, Universidade Estadual de Ponta Grossa, Av. Carlos Cavalcanti, 4748, \\ 84030-900, Ponta Grossa, PR, Brasil, \\ ${ }^{2}$ Departamento de Farmácia, Universidade Federal do Paraná, Av. Pref. Lothário Meissner 632, 80210-170, \\ Curitiba, PR, Brasil
}

\begin{abstract}
RESUMO: Symphytum officinale L. (Boraginaceae) é uma erva perene conhecida como confrei, consólida-maior e erva-do-cardeal, empregada na fitoterapia como antiinflamatório, emoliente e anestésico suave de uso tópico, devido à ação da alantoína encontrada nos órgãos subterrâneos e na folha. Com a finalidade de contribuir com a identificação da planta medicinal e da droga vegetal, foram realizados estudos morfoanatômicos de raiz e rizoma, em estrutura secundária. O material botânico foi fixado e preparado de acordo com microtécnicas usuais. Os órgãos subterrâneos são semelhantes, fusiformes e mostram-se de cor amarela clara a negra. A raiz e o rizoma apresentam periderme e tecidos vasculares secundários semelhantes, mas diferem pela presença de xilema primário exarco na raiz e xilema primário endarco e medula parenquimática no rizoma. Numerosas células parenquimáticas contendo mucilagem e amiloplastos são observadas na raiz e no rizoma.
\end{abstract}

Unitermos: Symphytum officinale, Boraginaceae, morfoanatomia, raiz, rizoma.

\begin{abstract}
Morpho-anatomical characterization of the root and rhizome of Symphytum officinale L. (Boraginaceae)". Symphytum officinale L. (Boraginaceae) is a perennial herb known as comfrey, gum plant or boneset, and it is employed topically as anti-inflammatory, emollient and mild anesthetic in phytotherapy, due to allantoin found in the underground organs and leaf. In order to contribute to the medicinal plant and vegetal drug identification, morpho-anatomical investigations of the root and rhizome, in secondary growth, were carried out. The botanical material was fixed and prepared according to usual microtechniques. The underground organs are alike, slender and yellow to black coloured. The root and the rhizome show similar periderm and secondary vascular tissues, yet they differ in that the root shows exarch primary xylem, while the rhizome presents endarch primary xylem and parenchymatous pith. Numerous parenchymatic cells which contain mucilage and amyloplasts are observed in the root and rhizome.
\end{abstract}

Keywords: Symphytum officinale, Boraginaceae, morpho-anatomy, rhizome, root.

\section{INTRODUÇÃO}

Symphytum officinale L. (Boraginaceae) (Figura 1), conhecido popularmente como confrei, consólidamaior e erva-do-cardeal (Corrêa,1984; Cruz, 1995), é uma erva perene de caule curto, com cerca de $90 \mathrm{~cm}$ de altura (Sousa et al., 1991), que apresenta raiz e rizoma semelhantes externamente. Conseqüentemente, o rizoma é utilizado como raiz pela população e pela própria indústria farmacêutica, uma vez que as referências não fazem distinção entre esses órgãos subterrâneos na produção de fitoterápicos (Toledo, 2004).

A raiz, juntamente com as partes aéreas, foram recomendadas pela $\mathrm{RE} \mathrm{n}^{\circ} 89$ (Anvisa, 2004) na forma de extrato como cicatrizante de uso tópico, devido à presença de alantoína, substância ativa antiinflamatória (Blumenthal, 1998; PDR, 2000) e regeneradora tissular (Loots; Loots; Ws, 1979; PDR, 2000). Entretanto, é desaconselhada para uso interno devido a toxicidade atribuída aos alcalóides pirrolizidínicos (Mengue et al.,
2001). Bara e Vanetti (1997/1998) avaliaram o potencial antibacteriano de dezesseis espécies de plantas tidas como medicinais. O extrato hidroalcoólico de Symphytum officinale estava entre os menos ativos.

Sendo a identificação indispensável quando se pretende utilizar uma droga vegetal no preparo de medicamentos, a morfologia é um dos aspectos importantes. Cada órgão vegetal apresenta características morfológicas próprias que devem ser comparadas com a droga vegetal padrão ou com monografias especializadas (Oliveira; Akisue; Akisue, 1998). O presente trabalho procurou fornecer informações sobre a identificação morfoanatômica da raiz e do rizoma de $S$. officinale, que vêm sendo empregados pela indústria farmacêutica na produção de cremes, pomadas e géis (Soares et al., 1986; Toledo et al., 2003).

\section{MATERIAL E MÉTODOS}

\section{Material botânico}



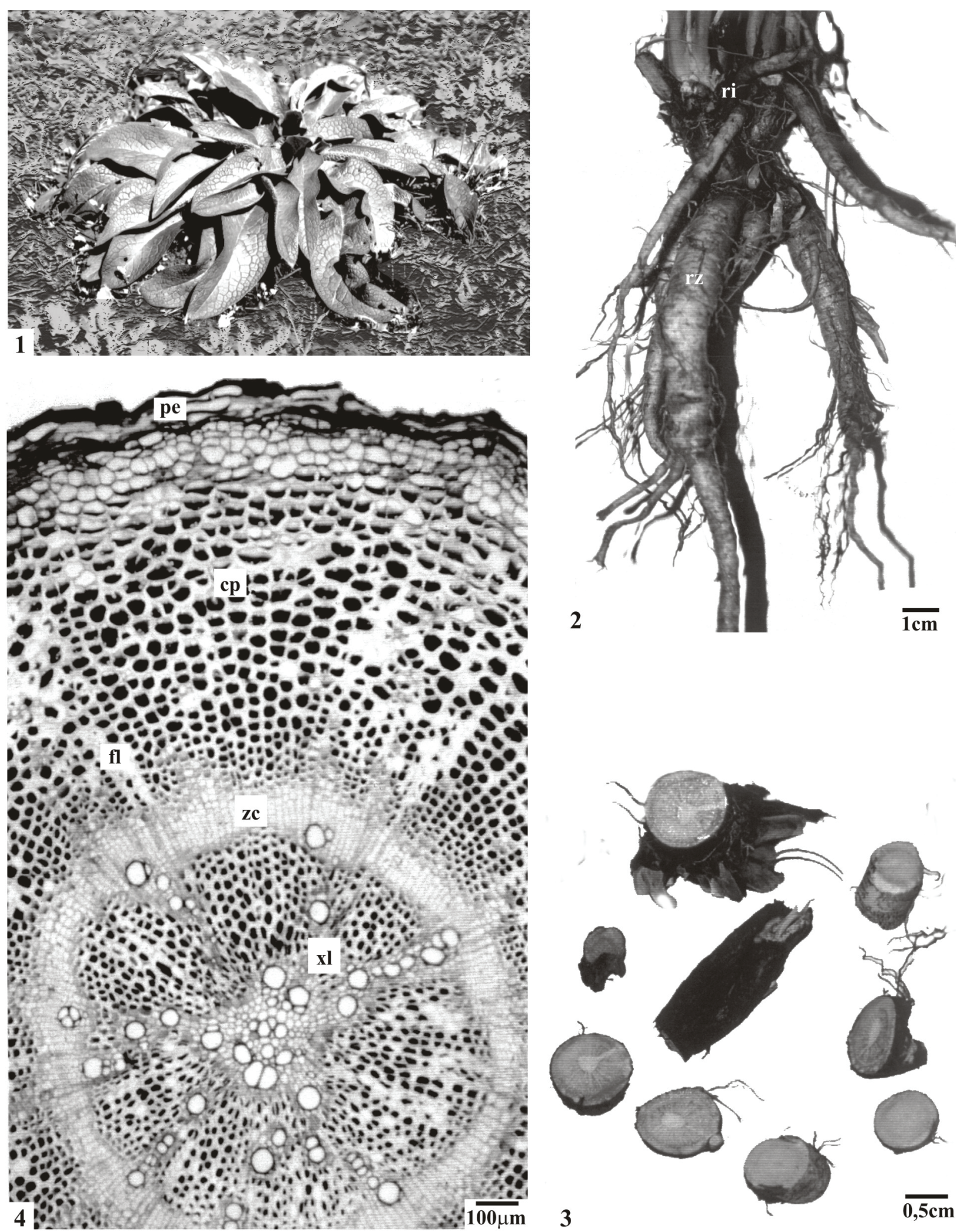

Figuras 1-4. Symphytum officinale L.: 1. aspecto geral do vegetal no hábito; 2. detalhe dos órgãos subterrâneos, rizoma (ri) e raiz (rz); 3. fragmentos dos órgãos subterrâneos, mostrando região central clara e periférica raiada; 4. secção transversal da raiz, indicando periderme (pe), células parenquimáticas (cp), floema (fl), zona cambial (zc) e xilema (xl). 
A coleta de $S$. officinale foi realizada no Parque Castelo Branco, região metropolitana de Curitiba, altitude de $911 \mathrm{~m}$, coordenadas $25^{\circ} 23^{\prime} 03^{\prime \prime} \mathrm{S}$ e $45^{\circ} 07^{\prime}$ 02 " W, no período da manhã, em junho de 2002 e julho de 2003. Foram também coletados exemplares floridos para confecção de exsicata, a qual foi depositada no Herbário do Museu Botânico Municipal de Curitiba sob registro MBM 269350.

\section{Metodologia}

Amostras de raiz e rizoma foram fixadas em FAA 70 (Johansen, 1940), o qual foi posteriormente descartado e substituído por etanol a 70\% (Berlyn; Miksche, 1976). $\mathrm{O}$ material foi analisado em estrutura secundária, sendo confeccionadas lâminas semipermanentes por meio de secções transversais e longitudinais feitas à mão livre, utilizando-se isopor como suporte (Quintas, 1963). Para as lâminas permanentes utilizou-se a técnica de inclusão em glicol-metacrilato, de acordo com as indicações do fabricante $\left(\right.$ Leica $^{\circledR}$ ) e segundo Feder e O’Brien (1968), e procedeu-se ao seccionamento no micrótomo rotatório Spencer 820, obtendo-se secções de 7 a $9 \mu \mathrm{m}$ de espessura. Os cortes foram distendidos nas lâminas e secos em mesa térmica a $40{ }^{\circ} \mathrm{C}$. Como meio de montagem foi usado Entellan $^{\circledR}$. Empregaram-se as colorações com azul de toluidina (O’Brien; Feder; McCully, 1965; Sakai, 1973) ou com azul de astra e fucsina básica (Roeser, 1962; Brito; Alquini, 1996). O registro fotográfico foi efetuado no microscópio fotônico Olympus $\mathrm{BX} 40$, acoplado à unidade de controle PM 20.

O reconhecimento de metabólitos celulares foi realizado com cloreto férrico para verificação de compostos fenólicos (Johansen, 1940), lugol para amido (Berlyn; Miksche, 1976), azul de metileno para mucilagem (Oliveira; Saito, 1991), floroglucina clorídrica para lignina (Foster, 1949) e Sudan III para substâncias lipofílicas (Sass, 1951).

\section{RESULTADOS}

\section{Morfologia externa}

A raiz e o rizoma (Figuras 2, 3) são semelhantes, fusiformes, de comprimento e espessura variáveis, de crescimento perpendicular à superfície, com aspecto mucilaginoso quando frescos e quebradiços e duros após secagem. Externamente, apresentam-se de cor amarela clara a castanha ou negra, com fendas profundas no sentido longitudinal, sendo as raízes constituídas de pequenas cicatrizes circulares deixadas pelo destacamento das ramificações laterais. Em secção transversal (Figura 3), mostram-se de cor amarela clara, podendo-se distinguir um anel central de mesma cor e externamente a este, uma região raiada de tonalidade marrom.

\begin{tabular}{l|l}
187 & $\begin{array}{l}\text { Rev. Bras. Farmacogn. } \\
\text { Braz J. Pharmacogn. }\end{array}$
\end{tabular} 16(2):abr/jun. 2006

\section{Anatomia}

A raiz, em estrutura secundária, tem o sistema de revestimento representado pela periderme (Figuras $4,5)$. O súber é formado de 7 a 10 camadas de células tabulares achatadas, de tamanhos variados, apresentando compostos fenólicos, e a feloderme é distinguível. Subjacentemente, ocorrem vários estratos de células parenquimáticas, de diversos tamanhos, aclorofiladas, contendo mucilagem e repletas de amiloplastos com grãos de amido simples e compostos, em número aproximado de 6 (Figura 5). No cilindro vascular, o câmbio forma floema centrifugamente e xilema de modo centrípeto (Figura 4). O floema secundário compõe-se de elementos crivados, células companheiras e numerosas células parenquimáticas, que possuem no interior mucilagem e amiloplastos (Figura 6). O xilema secundário é formado por elementos traqueais dispostos radialmente, sendo intercalados por células parenquimáticas de paredes delgadas, não lignificadas e com conteúdo mucilaginoso (Figura 7). Na região central, distinguem-se os elementos condutores do xilema primário, onde o protoxilema ocupa posição externa ao metaxilema (Figura 8 ).

$\mathrm{O}$ rizoma, em estrutura secundária, apresenta periderme (Figura 9), podendo o felogênio ser evidenciado, e forma súber em direção à periferia, que consiste de células tabulares com substâncias fenólicas. O córtex compreende diversas camadas de células parenquimáticas de paredes delgadas e que contêm mucilagem (Figura 9). No cilindro vascular, o câmbio forma floema em direção à periferia e xilema de modo centrípeto (Figuras 10,11), sendo mais ativo na região intrafascicular. Comparativamente, há grande formação de células parenquimáticas em relação aos elementos condutores. Os elementos traqueais se dispõem isoladamente ou em pequenos grupos (Figuras 10-12), e tendem a seguir uma gradação de diâmetro, na qual os elementos condutores de menor tamanho correspondem ao protoxilema e localizam-se na parte mais interna do cilindro xilemático. Raios parenquimáticos percorrem o xilema e o floema, e são compostos de 1 ou 2 fileiras de células. Na medula, as células são parenquimáticas, de paredes delgadas e repletas de mucilagem e amiloplastos.

\section{DISCUSSÃO}

A raiz é a parte do eixo do vegetal desprovida de folhas e suas modificações, geralmente com forma cilíndrica e adaptada a diferentes funções (Oliveira; Akisue, 1995). Usada como droga, raramente é de natureza primária (Matos; Matos, 1989). O rizoma, tipo de caule subterrâneo, de aspecto semelhante ao da raiz, é adaptado quase sempre às funções de armazenar reservas e de reprodução (Oliveira; Akisue, 1995). Numerosas drogas são constituídas concomitantemente por raiz e rizoma e a diferenciação entre os mesmos, após a transformação em droga, nem sempre é fácil, sendo esses 

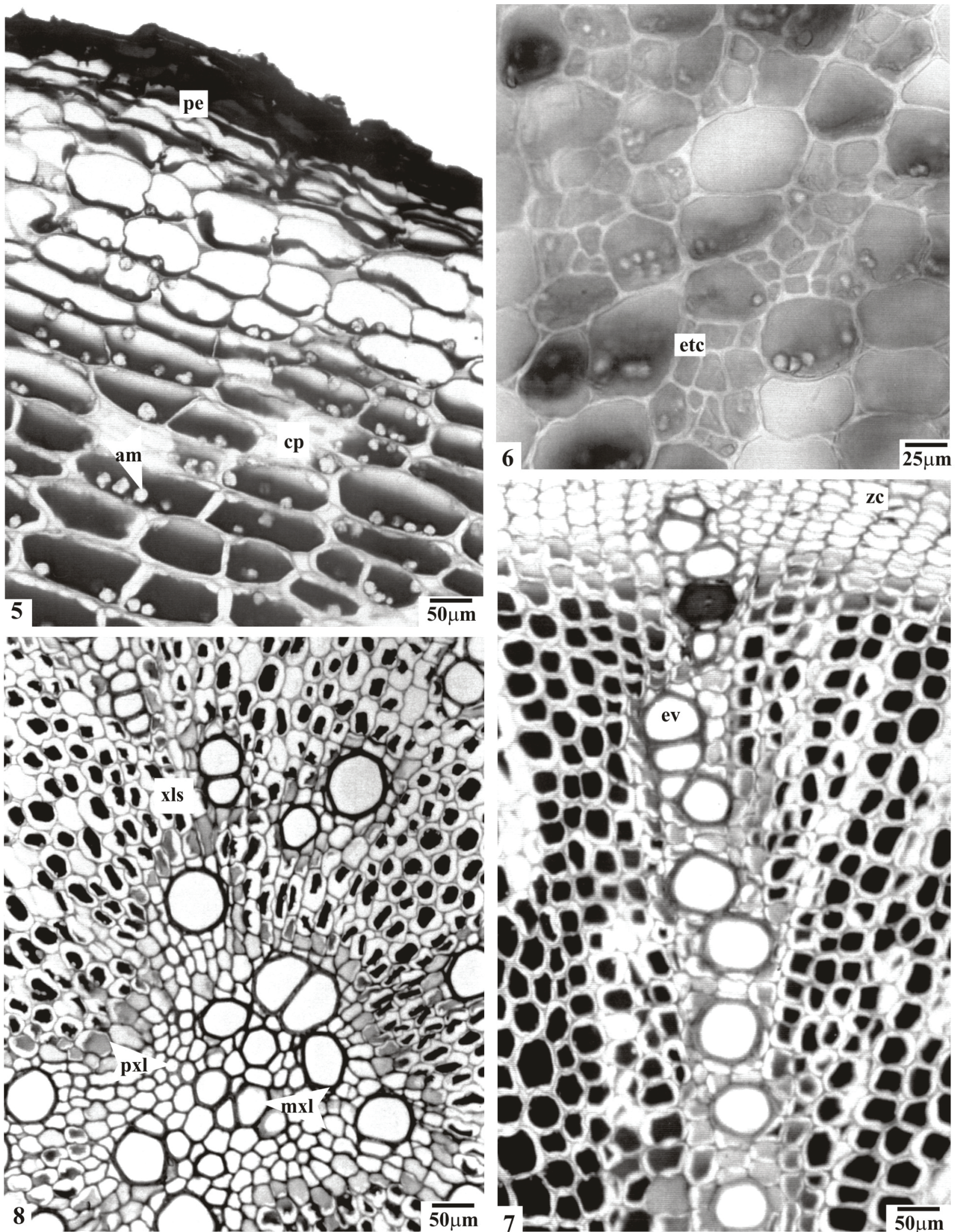

Figuras 5-8. Symphytum officinale L. - raiz, em estrutura secundária: 5. pormenor da periderme (pe) e das células parenquimáticas (cp), que contêm mucilagem e amiloplastos $(\mathrm{am})$; 6. elementos de tubo crivado (etc) em meio a células companheiras e células parenquimáticas do floema; 7. zona cambial (zc) e elementos de vaso (ev) enfileirados separados por numerosas células parenquimáticas com conteúdo mucilaginoso; 8. região central, indicando o xilema secundário (xls) e a posição do protoxilema (pxl) e do metaxilema (mxl). 

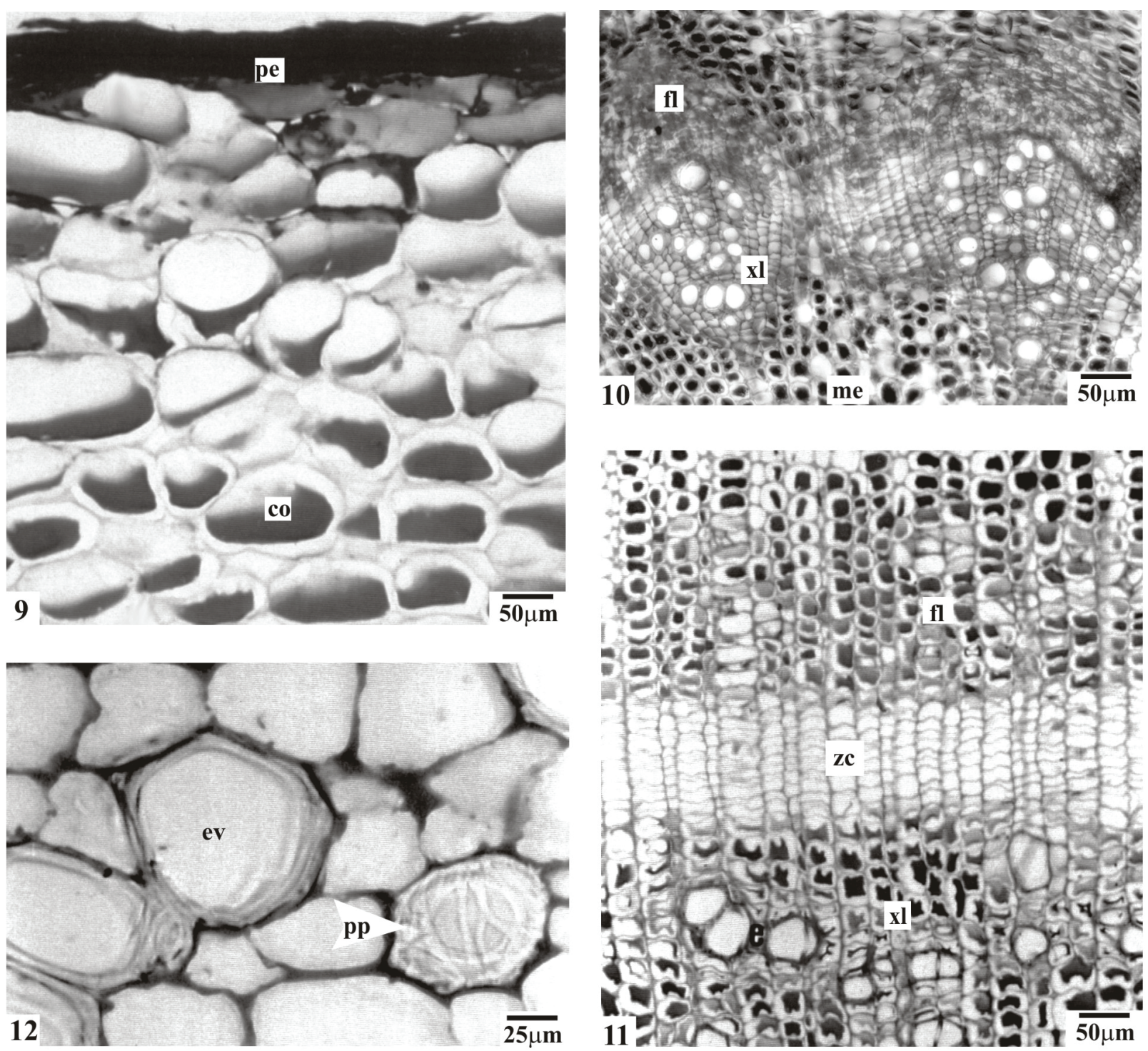

Figuras 9-12. Symphytum officinale L.- rizoma, em estrutura secundária: 9. periderme (pe) constituindo o sistema de revestimento e região cortical (co); 10. organização do sistema vascular, mostrando floema (fl), xilema (xl) e parte da medula (me); 11. floema (fl) e xilema (xl) com numerosas células parenquimáticas contendo mucilagem e zona cambial evidente (zc); 12. detalhe de elementos de vaso (ev) e de uma placa de perfuração (pp).

órgãos a parte vegetal citada em muitas monografias da Farmacopéia Brasileira (Oliveira; Akisue; Akisue, 1998). A BHP (1990) não faz distinção entre raiz e rizoma na monografia de $S$. officinale e produtos fitoterápicos à base de confrei são elaborados com a porção subterrânea, considerada como raiz. Os resultados referentes à morfologia externa neste trabalho foram coincidentes com os encontrados na BHP (1990) e no PDR (2000), e discordantes do observado por Grieve (1998), que cita para $S$. officinale rizoma pequeno e horizontal. Diferindo da pigmentação vermelha considerada comum em raiz de representantes de Boraginaceae (Metcalfe; Chalk, 1950), a espécie analisada apresenta órgãos subterrâneos internamente de coloração amarela.

Com referência à organização estrutural, a raiz e o rizoma de $S$. officinale seguem o padrão comum observado em muitas Magnoliopsida herbáceas (Esau, 1977) e correspondem à descrição da monografia do confrei (BHP, 1990). Nesta investigação, esses órgãos mostram-se muito semelhantes, quanto ao sistema de revestimento e ao conteúdo das células parenquimáticas. De acordo com Esau (1977), o conteúdo destas células pode variar acentuadamente em relação às atividades metabólicas que desempenham. Diversos tipos de inclusões podem ser encontrados, e entre as orgânicas, destacam-se grãos de amido, cristais de oxalato de 
cálcio e mucilagem (Oliveira; Akisue; Akisue, 1998). Considerada um constituinte natural de algumas espécies vegetais e, portanto, não indicativa de alterações patológicas na planta (Oliveira; Akisue; Akisue, 1998), a mucilagem pode ser secretada por idioblastos, cavidades, dutos, superfícies epidérmicas, tricomas, emergências e parênquima (Castro; Machado, 2003). Metcalfe e Chalk (1950) descrevem células secretoras com conteúdo não identificado no córtex e na medula de Symphytum, provavelmente equivalentes às células parenquimáticas mucilaginosas encontradas neste trabalho. A grande quantidade de mucilagem, aproximadamente $29 \%$, contribui na indicação de $S$. officinale no tratamento tópico de pele e mucosas (Alonso, 1998), porque possui atividade protetora, devido à ação mecânica de recobrimento das áreas irritadas e inflamadas, isolandoas de agentes agressivos, e ao efeito antiinflamatório e emoliente, reidratando e suavizando a área irritada pela capacidade de captar água (Kuklinski, 2000).

Quanto aos grãos de amido, são considerados parte da reserva vegetal (Von Poser, 2002) e a observação feita na espécie em questão é similar à descrita na BHP (1990) para $S$. officinale, na qual foram citados grãos de amido arredondados, simples ou compostos de 2 ou 3, com hilo estrelado. No gênero Symphytum, cristais de oxalato de cálcio são incomuns (Metcalfe; Chalk, 1950), não sendo observados na espécie em questão.

Periderme ocorre em Magnoliopsida herbáceas, especialmente nas porções mais velhas de raiz e caule (Esau, 1977) e é o sistema de revestimento dos órgãos subterrâneos investigados. De acordo com Esau (1977), Mauseth (1988) e Fahn (1990), em caule o primeiro felogênio surge superficialmente, sendo posteriormente instalado em camadas mais profundas. No entanto, em raiz esse meristema lateral é formado em regiões internas, usualmente no periciclo, o que resulta no descarte subseqüente do córtex e da epiderme. Tal eliminação é confirmada em Boraginaceae por Metcalfe e Chalk (1950). Desse modo, a constatação de parênquima multiestratificado entre a periderme e o sistema vascular da raiz de $S$. officinale pode ter origem pericíclica. Esse tecido, que delimita externamente o cilindro vascular e que comumente é unisseriado, pode consistir de várias camadas de células parenquimáticas de paredes delgadas (Fahn, 1990) e, em Boraginaceae, geralmente não apresenta esclerênquima (Metcalfe; Chalk, 1950).

$\mathrm{Na}$ raiz e no rizoma de $S$. officinale, o arranjo do sistema vascular secundário compreende um cilindro floemático externo ao xilemático. No entanto, a ausência de medula na raize a diferenciação centrípeta dos elementos traqueais do xilema primário nesse órgão permitem a distinção entre a raiz e o rizoma. Segundo Esau (1977), Mauseth (1988) e Fahn (1990), os elementos condutores do protoxilema são externos aos do metaxilema na raiz, o que caracteriza o xilema como exarco. $\mathrm{Na}$ opinião de Mauseth (1988), embora seja difícil identificar o último elemento do protoxilema e o primeiro do metaxilema no caule, quando a transição é uniformemente gradual, os elementos traqueais de menor diâmetro referem-se ao protoxilema e estão dispostos na parte mais interna do xilema, caracterizando-o como endarco. Adicionalmente, em concordância com os resultados de $S$. officinale, a medula é usualmente não lignificada e compõe-se de grandes células parenquimáticas, de paredes delgadas na família (Metcalfe, Chalk, 1950).

\section{AGRADECIMENTOS}

Ao taxonomista Dr. Gert Guenther Hatschbach, do Museu Botânico Municipal de Curitiba, pela identificação da espécie.

\section{REFERÊNCIAS}

Alonso JR 1998. Tratado de fitomedicina - bases clínicas y farmacológicas. Buenos Aires: Isis.

Anvisa. Resolução RE no 89 de 16 de março de 2004. Determina a publicação da lista de registro simplificado de fitoterápicos. Relator: Davi Rumel. Diário Oficial da República Federativa do Brasil, Brasília, 18 de mar. 2004.

Bara MTF, Vanetti MCD 1997-1998. Estudo da atividade antibacteriana de plantas medicinais, aromáticas e corantes naturais. Rev Bras Farmacogn 7-8: 21-34.

Berlyn GP, Miksche JP 1976. Botanical microtechnique and cytochemistry. Ames: Iowa State University.

BHP - British Herbal Pharmacopoeia 1990. Bournemouth: British Herbal Medicine Association. v. 1.

Blumenthal M, Goldberg A, Brinckmann J, Foster S, Tyler VE 1998. Complete German commission E monographs - therapeutic guide to herbal medicines. Austin: American Botanical Council.

Brito JFA, Alquini Y 1996. A new method for staining botanical material embedded in glycol methacrylate (GMA). Arq Biol Tecnol 39: 949-951.

Castro MM, Machado, SR 2003. Células e tecidos secretores. In: Appezzato-da-Glória B, Guerreiro SMC. Anatomia vegetal. Viçosa: UFV.

Corrêa MP 1984. Dicionário das plantas úteis do Brasil e das exóticas cultivadas. Rio de Janeiro: Imprensa Nacional. v. 5.

Cruz GL 1995. Dicionário das plantas úteis do Brasil. 5.ed. Rio de Janeiro: Bertrand Brasil.

Esau K 1977. Anatomy of seed plants. $2^{\text {nd }}$ ed. New York: John Wiley.

Fahn A 1990. Plant anatomy. $4^{\text {th }}$ ed. Oxford: Pergamon Press.

Feder N, O'Brien TP 1968. Plant microtechnique: some principles and new methods. Am J Bot 55: 123-142.

Foster AS 1949. Practical plant anatomy. $2^{\text {nd }}$ ed. Princeton: D. Van Nostrand.

Grieve M 1998. A modern herbal - the medicinal, culinary, cosmetic and economic properties, cultivation and folklore of herbs, grasses, fungi, shrubs and trees with all their modern scientific uses. London: Tiger Books International.

Johansen DA 1940. Plant microtechnique. New York: McGrawHill Book.

Kuklinski C 2000. Farmacognosia - estudio de las drogas 
y sustancias medicamentosas de origen natural. Barcelona: Omega.

Loots JM, Loots GP, Ws J 1979. The effect of allantoin on cellular multiplication in degenerating and regenerating nerves. South Afr Med J 55: 53-56.

Matos JMD, Matos MEO 1989. Farmacognosia: curso teóricoprático. Fortaleza: EUFC.

Mauseth JD 1988. Plant anatomy. Menlo Park: Benjamin Cummings.

Mengue SS, Mentz LA, Schenkel EP 2001. Uso de plantas medicinais na gravidez. Rev Bras Farmacogn 11:2135.

Metcalfe CR, Chalk L 1950. Anatomy of dicotyledons: leaves, stem, and wood in relation to taxonomy with notes on economic uses. Oxford: Clarendon Press. v. 2.

O'Brien TP, Feder N, McCully ME 1965. Polychromatic staining of plant cell walls by toluidine blue $\mathrm{O}$. Protoplasma 59: 368-373.

Oliveira F, Saito ML 1991. Práticas de morfologia vegetal. São Paulo: Atheneu.

Oliveira F, Akisue G 1995. Fundamentos de farmacobotânica. Rio de Janeiro: Atheneu,.

Oliveira F, Akisue G, Akisue MK 1998. Farmacognosia. São Paulo: Atheneu.

PDR for herbal medicines 2000. $2^{\text {nd }}$ ed. New Jersey: Medical Economics.

Quintas AT 1963. Novo material de apoio para cortes histológicos. Rev Fac Agron UFRGS 6: 51-55.

Roeser KR 1962. Die Nadel der Schwarzkiefer-Massenprodukt und Kunstwerk der Natur. Mikrokosmos 61: 33-6.

Sakai WS 1973. Simple method for differential staining of paraffin embedded plant material using toluidine blue O. Stain Technol 43: 247-249.

Sass JE 1951. Botanical microtechnique. $2^{\text {nd }}$ ed. Ames: Iowa State College.

Soares IC, Nicoletti MA, Consiglieri VO 1986. Incorporação de extrato flúido de Symphytum officinale L. em cremes evanescentes. Rev Bras Farmacogn 1(Supl. 1): 42

Sousa MP, Matos MEO, Matos FJA, Machado MIL, Craveiro AA 1991. Constituintes químicos ativos de plantas brasileiras. Fortaleza: EUFC.

Toledo ACO, Duarte MR, Nakashima T 2003. Análise farmacognóstica da droga e do extrato fluido das folhas de Symphytum officinale L. (Boraginaceae). Rev Bras Farmacogn 13(Supl. 2): 1-2.

Toledo ACO. Estudos morfo-anatômico e fitoquímico, ensaios farmacopéicos e atividade antimicrobiana de órgãos subterrâneos e folha de Symphytum officinale $L$. (Boraginaceae). Curitiba, 92p. Dissertação (Mestrado) - Universidade Federal do Paraná, 2004.

Von Poser GL 2002. Polissacarídeos. In: Simões CMO, Schenkel EP, Gosmann G, Mello JCP, Mentz LA, Petrovick PR. Farmacognosia: da planta ao medicamento. 4.ed. Porto Alegre/Florianópolis: Universidade/UFRGS/ UFSC. 